\title{
Usando a psicologia positiva no atendimento nutricional
}

- Importância do autocuidado do profissional: o profissional que almeja ser um agente de mudança precisa iniciar o processo de mudança dentro de si. Para isso, o nutricionista (ou qualquer profissional) deve aprender a cuidar de si, tanto da sua saúde física quanto mental, emocional e espiritual. Desta forma, ele/ela cuidará melhor do seu paciente e compreenderá melhor o processo;

- Os estudos demonstram que a principal causa de morte são nossas escolhas pessoais. Das 2,4 milhões de morte nos EUA no ano 2000, 1 milhão poderia ter sido evitada se as pessoas tivessem mudado seus hábitos, como sedentarismo, má alimentação, altos níveis de estresse, falta de sono entre outros;

- De acordo com Martin Seligman, psicólogo pioneiro do movimento da Psicologia Positiva afirma que "objetivo da Psicologia Positiva é catalisar uma mudança... para parar de focar somente em consertar as piores coisas na vida mas sim na construção das melhores qualidades da vida";

- A Psicologia Positiva estuda a experiência subjetiva positiva, as potencialidades e virtudes humanas, bem como as instituições que promovem a qualidade de vida, com objetivo final de promover o florescimento das pessoas;

- Uma das formas de aplicar a psicologia positiva no atendimento nutricional é através do "saborear". O saborear é uso consciente de pensamentos e comportamentos que prolonguem, gerem ou intensifiquem o prazer de uma experiência, neste caso da alimentação (também conhecido como mindful eating). Estudos demonstram que comer com atenção plena (mindful eating), que inclui selecionar alimentos de forma consciente e saborear as refeições, auxilia na perda de peso;

- Outra aplicabilidade da Psicologia Positiva no atendimento nutricional é focar no positivo. Devemos comemorar e celebrar as pequenas conquistas dos clientes e deixar de realçar as dificuldades. Vitalidade emocional (cultivo de emoções positivas) reduz riscos de doença coronária, demonstra estudo;

- Para aumentar a autoestima e autoeficácia do paciente, precisamos identificar suas forças pessoais. Na Psicologia Positiva, foram classificadas 24 forças universais. O reconhecimento das forças auxilia na aplicação delas a favor do processo de adesão alimentar;

- Por último, é essencial que o profissional desenvolva a empatia, colocando-se no lugar do seu cliente sem julgamento. Ao mesmo tempo, é fundamental a promoção da autocompaixão no cliente para que ele siga em frente em momentos de recaída.

\section{Referências bibliográficas}

1. KEENEY, R.L. Personal Decisions Are the Leading Cause of Death. INFORMS; 56(6): 1335-1347, 2008.

2. SELIGMAN, M.E.P. "Florescer". Rio de Janeiro: Objetiva; 2011.

3. DUNN, C.; OLABODE-DADA, O.; WHETSTONE, L. et al. Mindful Eating and Weight Loss, Results from a Randomized Trial. J Family Med Community Health; 5(3): 1152, 2018.

4. KUBZANSKY, L.D.; THURSTON, R.C. Emotional vitality and incident coronary heart disease: benefits of healthy psychological functioning. Arch Gen Psychiatry; 64(12):1393-401, 2007.

5. NEFF, K.D. Self-Compassion: Stop beating yourself up and leave insecurity behind. New York: William Morrow, 2011.

6. FAIN, J. The Self-Compassion Diet: A Step-by-Step Program to Lose Weight with Loving-Kindness. Boulder Colorado: Sounds True, 2011. 